\title{
DETERMINATION OF ELLAGIC ACID BY CAPILLARY ELECTROPHORESIS IN ARGENTINIAN WINES
}

\author{
Adrian Spisso, Federico J. V. Gomez, and María Fernanda Silva* \\ Instituto de Biología Agrícola de Mendoza (IBAM-CONICET), Facultad de Ciencias Agrarias, \\ Universidad Nacional de Cuyo, Mendoza, Argentina.
}

Keywords: POLYPHENOLS IN WINE, GREEN ANALYTICAL METHODOLOGIES, CAPILLARY ZONE ELECTROPHORESIS, FUNCTIONAL FOODS

Running title: Ellagic acid by capillary electrophoresis in Argentinian wines from

\section{Abstract}

Rising interest in ellagic acid (EA) present in functional foods is supported by its antimutagenic, anticarcinogenic, antiviral, antibacterial and antioxidative effects. The present approach presents for the first time the determination of ellagic acid and other phenolics in wines by miniaturized solid phase extraction prior to capillary zone electrophoresis with UV. The extraction was performed using a home-made miniaturized pipette-tip column. The procedure allowed a significant reduction in conditioning/sample/washing/elution volumes. The effects of important factors affecting the extraction efficiency as well as electrophoretic performance were investigated to acquire optimum conditions. The analytes were separated within $10 \mathrm{~min}$ with a BGE containing $30 \mathrm{mmol} \mathrm{L}^{-1}$ sodium tetraborate $10 \% \mathrm{v} / \mathrm{v} \mathrm{MeOH} \mathrm{pH} \mathrm{9.10.} \mathrm{The} \mathrm{optimized} \mathrm{method}$ was applied to the determination of ellagic acid in commercial and pilot-scale wines. Indeed, the content of EA was correlated with viticultural parameters such as grape varietal, production area, and aging conditions (oak wood guard and glass bottle ward). In order to validate the results, a comparison between the CZE and HPLC data was made.

Received: 12 21, 2017; Revised: 02 27, 2018; Accepted: 03 09, 2018

This article has been accepted for publication and undergone full peer review but has not been through the copyediting, typesetting, pagination and proofreading process, which may lead to differences between this version and the Version of Record. Please cite this article as doi: 10.1002/elps.201700487.

This article is protected by copyright. All rights reserved. 
Key words: ellagic acid; wines; capillary zone electrophoresis, miniaturized SPE

\section{Introduction}

Nowadays, increasing scientific evidence support the concept that functional foods containing bioactive compounds promote optimal health and help to reduce the risk of disease [1]. More than fifty years of study have unquestionably demonstrated a direct correlation between diets rich in fruits, vegetables and dietary fibers and reduced risk of cancer (mainly epithelial cancers of the alimentary and respiratory tracts) [2-5].

Nutraceuticals (a hybrid term between nutrients and pharmaceuticals, coined by De Felice in 1989) have received much attention in recent years from researchers, consumers and food makers [6]. The list of nutraceutical compounds is boundless, including vitamins, probiotics, bioactive peptides, and a vast number of antioxidants $[7,8]$. The most important phytochemicals are phenolics, and carotenoids. It is well known that berries are rich in phenolic compounds usually concentrated in the skin. This allocation is associated to their principal natural function; to protect the plant against environmental stress and pathogens [9]. Owing to their antioxidant abilities, phenolic compounds are able to reduce the incidence of serious chronic diseases, reduce plasma oxidation stress and slow aging [1014]. Indeed, it has been demonstrated that inflammation and apoptosis could have detrimental effects on brain cell function and natural antioxidants have a major role in neuroprotective effects [15]. Phenolic compounds are also considered as preservatives in foods and beverages thanks to their antimicrobial and antioxidant abilities [9].

Wines, especially red wines, contain plant secondary metabolites with promising health benefits [5]. The quality of wine is correlated with grape berry phenolic profile since these compounds have a great impact on the sensorial characteristics, especially color and flavor. Their content depends on both variety and terroir [16]. Terroir is the dynamic interaction among the environment, the grapevine plant and the imposed viticultural techniques [17].

Ellagic acid (EA, 2,3,7,8-tetrahydroxybenzopyrano [5,4,3-cde]benzopyran-5-10-dione) is a flavonoid, dimeric derivative of gallic acid. It is found in at least 46 fruits, including 
pomegranate, grape, raspberry, strawberry, cranberry, and nuts. EA is a highly thermodynamically stable molecule and exhibits the ability to scavenge free radicals and chelate metal ions [18]. EA has acknowledged great relevance in the scientific community in the last years; it has been reported to show different pharmacological effects, including antimutagenic, antiviral, antibacterial, anti-inflammatory and skin whitening properties. [19-26]. The anti-cancer properties of EA include induction of cell cycle arrest and apoptosis, and inhibition of tumor formation and growth [20].

Remarkably, despite the unquestionable knowledge supporting the health benefits of EA, there is scarce information on the presence of this molecule in wines. Talcott and Lee studied EA in wines and juices in Muscadine grapes (Vitis rotundifolia) [27]. They concluded that winemaking procedures and juice production methods have great impact on antioxidant flavonoids and ellagic acid contents. Crozier and col evaluated the influence of some oak wood-derived compounds, including ellagic acid, on the levels of anthocyanins and tannins in artificial wines [28]. Prida and Puech investigated and compared the chemical compositions of East European with American and French oaks [28-30]. They concluded that ellagitannins contribute to the classification of oak samples according to their geographical origin. Thus, the presence of EA in wines is influenced by grape varietal as well as winemaking process.

Liquid chromatography and capillary electrophoresis are the techniques of choice for the separation and determination of polyphenols. The determination of EA is generally performed by HPLC [31-35]. EA has already been determined by CE in industrial pulp samples and its filtrates [36]. High efficiency, minimal sample volume, low cost, and relatively short analysis times make CE a favorable separation technique.

Solid phase extraction (SPE) is one of the most used procedures to perform sample preparation in the analysis of phenolic compounds, [37]. The polyphenols are generally extracted from the samples using commercial cartridges with C8 and C18 columns[38]. Furthermore, miniaturized SPE is an important tool for preconcentration procedures because it employs significantly smaller amounts of sorbent material as well as minimal sample and reagent consumption [39]. 
To the best of our knowledge, there is no report on the determination of EA in commercial wines by CE. The aim of the current work was to develop a fast, simple, robust, sensitive and low cost method for the extraction and determination of EA by miniaturizedsolid phase extraction prior to capillary zone electrophoresis in red, white and rose wines samples. The extraction of phenolic compounds from wine was performed using a homemade miniaturized column with $5 \mathrm{mg}$ of strata $\mathrm{X}$ as sorbent material. The optimized method was applied for the analysis of commercial and experimental wines. Indeed, a pilot-scale wine was elaborated in order to count with a traceable sample. The content of EA was correlated with viticulture parameters such as grape varietal, origin, vintage and aging process. In order to validate the obtained results, a comparison between the CZE data and the results obtained by previously optimized HPLC method was performed.

\section{Materials and Methods}

\subsection{Samples, Chemicals and Reagents}

Boric acid, acetonitrile and methanol were provided by J.T. Baker (Xalostoc, Mexico). Sodium hydroxide was provided by Merck (Buenos Aires, Argentina). Ellagic acid and other polyphenols were provided by Sigma Aldrich (St. Louis, MO, USA). Bonded silica sorbents were provided by Phenomenex (USA); C8 (particle size: $56 \mu \mathrm{m})$, C18 $(55 \mu \mathrm{m})$, and Strata-X (28- $34 \mu \mathrm{m})$. Ultrapure water $(18 \mathrm{M} \Omega \mathrm{cm})$ was obtained from Milli-Q system (Millipore, Bedford, MA, USA).

Thirty commercial and experimental wine samples from red, white and rose grapes of Vitis Vinifera L., harvested between 2010 and 2016, were analyzed. Wines were provided by collaborating wineries of Mendoza, Salta and La Pampa (Argentina), including an experimental winery from Facultad de Ciencias Agrarias (FCA), Universidad Nacional de Cuyo, Mendoza, Argentina. The following varieties were studied: Malbec, Torrontes, Cabernet Franc, Chardonay, Sauvignon Blanc, Merlot, Syrah, Pinot Gris, Pinot Noir and Pedro Gimenez. The comercial wineries were: Peñaflor, Cavas La Capilla, Alpamanta, Bodega del 
Desierto, Bodega La Rural, Familia Giaquinta, Piedra Negra, Fecovita, Bousquet, ,Tupun, Catena Zapata, Bodega La Celia, Atamisque, Benvenuto, El Tolombon and El Alto.

Experimental wines are elaborated under standardized conditions and in low quantities considering that their use is only for research purposes. So, a pilot scale winemaking was carried out according to the following procedure: $150 \mathrm{~kg}$ of Malbec grapes of three rows were randomized sampled, destemmed, and crushed, and introduced into the fermentation stainless steel tanks. The must was sulfited $\left(50 \mathrm{mg} \mathrm{L}^{-1}, \mathrm{~K}_{2} \mathrm{~S}_{2} \mathrm{O}_{5}\right)$ and after $24 \mathrm{~h}$, it was inoculated with $20 \mathrm{~g} \mathrm{~h} \mathrm{~L}^{-1}$ of the commercial S. cerevisiae bayanus yeast EC1118 (Lallemand, Montreal, Canada). The fermentation temperature was maintained at $25^{\circ} \mathrm{C} \pm 1$ ${ }^{\circ} \mathrm{C}$ until the end of the fermentation process. Pumping over and basic controls were carried out daily. When the alcoholic fermentation was completed (10 days), wines were sulfited $\left(50 \mathrm{mg} \mathrm{L}^{-1}\right.$ ) and filtered. Temperature was maintained at $7{ }^{\circ} \mathrm{C}$. Finally, wines were bottled 3 months after its preparation.

The wine samples were transferred under nitrogen to completely filled amber glass bottles, and stored at $4{ }^{\circ} \mathrm{C}$ to ensure their preservation until their analysis in the laboratory.

\subsection{Instrumentation and procedure}

Capillary electrophoresis was carried out using a Capel TM 105M (Lumex, St Petersburg, Russia) equipped with an UV detector and a 0-25 kV high-voltage power supply. The data were collected on a PC configured with Elforun software version 3.2.2. The capillary columns used for separation were bare fused-silica capillaries $57 \mathrm{~cm}$ full length, 50 $\mathrm{cm}$ effective length, $75 \mu \mathrm{m}$ ID and $375 \mu \mathrm{m}$ OD from MTC Micro Solv Technology Corporation (Eatontow, USA). The capillary tube was conditioned daily prior to its use by flushing with water (5min), $0.1 \mathrm{~mol} \mathrm{~L}^{-1} \mathrm{NaOH}$ for $5 \mathrm{~min}$, water for 5 mins, and, finally, with the running buffer for $5 \mathrm{~min}$. The separation voltage was $20 \mathrm{kV}$ and the capillary temperature was $20^{\circ} \mathrm{C}$. Samples were injected by hydrodynamic injection at 10 mbar for $3 \mathrm{~s}$. Electropherograms were recorded at $254 \mathrm{~nm}$. Between runs, the capillary was flushed with water ( $3 \mathrm{~min}$ ), 0.10 $\mathrm{mol} \mathrm{L}^{-1} \mathrm{NaOH}$ (3 $\left.\mathrm{min}\right)$, water ( $3 \mathrm{~min}$ ) and buffer ( $3 \mathrm{~min}$ ). Finally, the capillary tube was rinsed with $0.1 \mathrm{~mol} \mathrm{~L}^{-1} \mathrm{NaOH}$ for $10 \mathrm{~min}$, then with water for $10 \mathrm{~min}$, every day after use. The 
buffer used for separation was boric acid $\mathrm{pH}$ 9, with addition of $10 \% \mathrm{MeOH}$ as organic modifier.

The HPLC instrument was a Dionex Ultimate 3000 (Dionex Softron GmbH, Thermo Fisher Scientific Inc., Germering, Germany) consisting of vacuum degasser unit, autosampler, quaternary pump and chromatographic oven. The detector was a Dionex MWD-3000 (RS) model. The working wavelength was fixed at $254 \mathrm{~nm}$. The Chromeleon 7.1 software was used to control all the acquisition parameters of the HPLC-MWD system and also to process the obtained data. A Zorbax SB-Aq column (4.6 mm x $150 \mathrm{~mm}, 5 \mu \mathrm{m}$ ) Agilent Technologies was used. Ultrapure water with $0.1 \%$ Formic acid $(A)$ and Acetonitrile (B) were used as mobile phases. The following gradient was used: 0-8.5 min, 10-30\% B; 8.5-10 min, $30-35 \% \mathrm{~B} ; 10-16 \mathrm{~min}, 35-75 \% \mathrm{~B} ; 16-18 \mathrm{~min}, 75-10 \% \mathrm{~B}$. The mobile phase flow was $1 \mathrm{~mL} \mathrm{~min}^{-}$ ${ }^{1}$. The column temperature was held at $20^{\circ} \mathrm{C}$ and the injection volume was $5 \mu \mathrm{L}$.

\subsection{Miniaturized SPE procedure}

Prior to the analysis of the samples by HPLC and CE, a miniaturized SPE extraction step was performed. The extraction of EA from wines was performed by SPE using a homemade column. Strata X, C8 and C18 cartridges (5 mg) were prepared in $1000 \mu \mathrm{L}$ pipette tips. Glass wool frits were used to keep the adsorbent material inside the tip. The pipette tip-SPE cartridges were conditioned with successive rinsing steps with $1 \mathrm{~mL}$ of ultrapure water and $1 \mathrm{~mL}$ of methanol, and then air-dried before sample loading. Filtered wine samples were introduced onto the activated column. Retained ellagic acid on the tip cartridge was eluted with $500 \mu \mathrm{L}$ methanol. The eluent was directly analyzed by CZE and HPLC.

\subsection{Data analysis}

All experimental results were statistically analysed using the InfoStat software (Universidad Nacional de Cordoba, Argentina). The statistical comparison was made by Tukey test at the 0.05 significance level. Data in the text and tables were expressed as mean \pm standard deviation $( \pm S D)$, and error bars in the figures and tables indicate standard deviation. 


\section{Results and Discussion}

\subsection{Sample clean-up}

Considering the complexity of wine matrix and the low concentration of the target analyte, the use of a clean-up step is particularly relevant. The extraction of EA from wines was performed by miniaturized-solid phase extraction (SPE) using home-made pipette tips cartidge. Several variables were tested in order to set up the optimal conditions for the extraction of EA in wines. Sorbent chemical nature, column assembly, and dilution solvent influenced the extraction efficiency and robustness. Real samples of wines were used for extraction procedure optimization, and electrophoretic peak areas were the analytical parameter for monitoring the process. The variation coefficients (CV) for optimization of extraction conditions were calculated as relative standard deviations of the corrected area (peak area/tr) analyses were carried out in triplicate.

Three kinds of bonded silica sorbents: C8 (particle size: $56 \mu \mathrm{m})$, C18 $(55 \mu \mathrm{m})$, and Strata-X (28- $34 \mu \mathrm{m}$ ) were evaluated. Cartridges were prepared in $1000 \mu \mathrm{L}$ pipette tips and varying amounts of sorbent (3-10 mg) in the miniaturized SPE device were evaluated by extracting 1 $\mathrm{mL}$ of wine. The highest peak-area response for EA was achieved when $5 \mathrm{mg}$ of Strata-X sorbent was employed, while no appreciable improvements were observed for higher

sorbent amounts (Figure 1S-A and B). In addition, glass wool was evaluated for packing the sorbent material into the tip. Adequate operational resistance was assessed for the whole miniaturized SPE procedure. The volume of the eluent was also evaluated. Taking into account the polarity of the phenolic compounds under study and the sorbent material, methanol was selected as eluent. Different volumes of $\mathrm{MeOH}$ were tested (200-1000 $\mu \mathrm{L})$. Complete analyte desorption was observed with $500 \mu \mathrm{L}$ of methanol (Figure 1S-C).

\subsection{Optimization of CZE parameters}

$E A$ is the dilactone of hexahydroxydiphenic acid. Although it has four ionizable groups, only two different pKa constants are distinguished. Deprotonation is observed at $\mathrm{pH}$ above 5.54 [40]. The latter is explained considering that EA is a symmetric dimer containing two hydroxyl equivalents in para-position and another two in meta-position with respect to the carbons that bind to each carbonyl group (Figure 1). 
In order to develop a capillary zone electrophoresis (CZE) method for simple and rapid determination of EA in wines, the effects of several experimental parameters upon the separation efficiency were systematically evaluated and optimized. The following parameters were consecutively optimized following the traditional one-at-a-time method: BGE $\mathrm{pH}$, composition and concentration, injection volume and mode, and other electrophoretic parameters such as electrophoretic separation voltage, and capillary temperature and conditioning. The first studied parameter was BGE composition and concentration. Boric acid, and sodium tetraborate were tested. Buffer concentrations of 20 - $75 \mathrm{mmol} \mathrm{L}^{-1}$ were tested. The effect of the buffer $\mathrm{pH}$ was studied within the range of $8.00-12.00$, adjusted by $0.50 \mathrm{~mol} \mathrm{~L}^{-1} \mathrm{HCl}$ or $0.50 \mathrm{~mol} \mathrm{~L}^{-1} \mathrm{NaOH}$, respectively. When the $\mathrm{pH}$ was lower than 8.5 separation efficiency was not satisfactory; complete overlapping of Cin and Sin, and partially overlapping of EA and Q peaks were observed. Increases in migration times as well in current were shown when the concentration of buffer increased. Resolution also improved for higher buffer concentrations, but no considerable improvements were observed for buffer concentrations above $30 \mathrm{mmol} \mathrm{L}^{-1}$. On the other hand, is is well known that organic modifiers can improve electrophotectic separations. In our system, the addition of an organic solvent clearly improved separation efficiency. ACN and $\mathrm{MeOH}(0-20 \% \mathrm{v} / \mathrm{v})$ were tested. Complete separation of the analytes was obtained with $10 \% \mathrm{v} / \mathrm{v} \mathrm{MeOH}$. Thus, the best results were obtained for a BGE containing $30 \mathrm{mmol} \mathrm{L}^{-1}$ sodium tetraborate and 10 $\% \mathrm{v} / \mathrm{v} \mathrm{MeOH}$ at $\mathrm{pH} 9.10$.

The effect of separation voltage was studied over the range 15-25 kV. $20 \mathrm{kV}$ was chosen as the optimum voltage to achieve an adequate compromise, in terms of sample throughput and resolution. The chosen conditions allow an acceptable current intensity of $11 \mathrm{~mA}$ without any appreciable Joule effect. The effect of temperature on electrophoretic

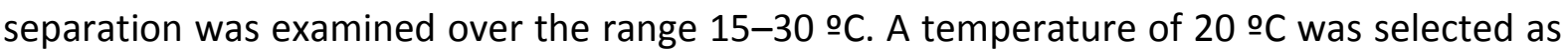
optimal. The optimal injection parameters were as follows: hydrodynamic injection 10 mbar, $3 \mathrm{~s}$.

A typical electropherogram for the standard mixture of phenolic compounds under the optimal conditions is shown in Figure 1A. Baseline separation for all analytes was achieved in 10 minutes. 
Additionally, in order to compare and contrast the performance of the developed CZE methodology, a previously developed HPLC methodology [41] was applied for the separation and quantification of EA in a mixture of polyphenol standards (Figure 1B). This approach (described in section 2.3) is routinely used for the analysis of polyphenols in different matrixes. Although better sensitivities were achieved using HPLC, large volumes of unsafe organic solvents were necessary for the chromatographic technique.

The optimized CZE method was then applied to determine phenolic compounds in wine samples. A representative electropherogram is shown in Figure 1C.

\subsection{Analytical performance}

With the purpose of evaluating the repeatability of the methodology, replicate injections of a standard mixture solution under the selected optimum conditions were carried out. In all cases, the RSD was less than $1.4 \%$ for the migration times and $2.8 \%$ for the peak areas $(n=3)$. The reproducibility (between-day precision) was also evaluated over 3 days by performing three injections each day. The \% RSD on the basis of migration times was $2.3 \%$ and peak areas was $10.2 \%$. The limits of detection (LOD) and quantification (LOQ) were evaluated on the basis on the following equations:

\section{LOD: 3 x Sc $\min / \mathrm{b}$}

\section{LOQ: $10 \times$ Sc $\min / \mathrm{b}$}

where Sc represents the standard deviation of the lowest concentration of the EA curve, and $b$ represent slope of the EA curve. Table 1 shows the analytical figures of merit.

After selecting the proper electrophoretic approach for wine samples, the effect of the matrix was assessed by comparing the signal of EA in pure solvent to the signal in the wine matrices. Eight concentrations of EA were used for each calibration curve: $0.5,1,2.5$, 5, 10, 15, 20 and $25 \mathrm{mg} \mathrm{L}^{-1}$. Matrix effect was calculated with the equation [42]:

$$
\text { Matrix effect } \%: 100-\left[\left(\frac{b \text { spiked }}{b \text { solvent }}\right) \times 100\right]=
$$

where $b$ is slope of calibration curve of standard addition and standard in solvent. 
No differences at migration time of EA were detected. As can be seen in Figure $2 \mathbf{S}$, we found a response reduction of $7.76 \%$ due to wine matrix interference. Considering that matrix effect is less than $10 \%$, quantification was carried out following the external calibration method.

In order to determine the accuracy of this method, $10 \mathrm{~mL}$ of red wine were divided into 10 aliquot of $1 \mathrm{~mL}$. The proposed method was applied to 6 aliquots and the average EA concentration determined was taken as a base value. Then, four levels of known quantities $(0.10,1.00,5.00$ and $10.00 \mathrm{mg} \mathrm{L}-1)$ of EA were added to the samples, and EA was determined following the optimized procedure $(n=3)$. The concentrations for recovery test were chosen according to the expected concentrations of phenolic compounds in wine. The recovery behavior was satisfactory; leading to recoveries higher than $93 \%$ and lower than $104 \%$.

\subsection{Sample Analysis}

The optimized methodology was applied to determine EA in 30 commercial and pilot-scale wines in order to study the effect of grape varietal, production area, and aging conditions on the content of this important flavonoid. Red, white and rose grape from different varietals, aging conditions and production areas were analyzed $(n=3)$. EA was only detected in red wines, while markedly differences were observed for red wines (Table 2).

These results could be attributed to the fact that polyphenols are extracted during crushing and fermentation when the juice is in contact with the grape skins and seeds. The accumulation of phenolic compounds is also affected by variety, climate, viticultural practices [16]. The concentration of EA in Malbec and Merlot wines were higher, but no correlation with production area or viticultural parameters were observed. Cabernet Franc was the varietal showing the lowest contents. Such findings indicate that EA could be a marker of botanical origin of red wines. Further studies are needed to confirm this potentiality with a higher number of traceable samples.

Figure 2 shows the mean concentration for EA in all Malbec samples under study for the different aging conditions (wood guard and glass bottle ward). Wines in contact with oak show 3 times higher amounts of EA. This conclusion indicates that the accumulation of EA is higher for wines that have been in contact with oak. Jordao et al [28] demonstrated in 
model wines that EA avoids the degradation of $(+)$-catechin and procyanidin B1. They concluded that the presence of EA influences anthocyanin content. Interesting perspectives arise for the use of EA as marker of wood guard, and the possibility of "tuning" the phenolic profile of premium wines by controlling the period of oak aging.

Additionally, the samples were also analysed with HPLC (as described in section 2.2) in order to provide a comparison with previous alternative methodologies. Considering all the pairs quantified with both methodologies, $68 \%$ of the comparisons showed \%RSD lower than $10 \%, 21 \%$ between $11 \%$ and $15 \%$, and the rest $11 \%$ between $15 \%$ and $20 \%$ (Figure 3 S). Thus, comparing the EA results, obtained by CZE and by LC procedure, it was concluded that both methods do not give significantly different values for the mean EA concentration.

\section{Conclusions and future perspectives}

In this work, the determination of EA in wines by miniaturized solid phase extractioncapillary zone electrophoresis is presented and evaluated for the first time. The present approach offers the possibility of performing robust, sensitive, cost effective and versatile simultaneous evaluation of phenolic compounds in different samples of oenological interest during winemaking and aging process. A simple SPE procedure using a miniaturized extraction scheme was carried out. This tip SPE technique allows an important decrease in conditioning/sample/washing/elution volumes. Our approach accomplishes the requirements for the analysis of polyphenols in wine and offers beneficial and comparable results with routine methodologies using HPLC.

The first conclusion regarding the analysis of samples is that red wines contain higher amounts of EA, supporting the health benefits related with red wine. Moreover, wine aging in oak increases the contents of EA. On the other hand, EA shows interesting perspectives as a marker of botanical origin of grapes. Interestingly Malbec varietal, the flag variety of Argentina, exhibits the highest amounts of EA. Additional research is necessary to confirm the potential health benefits of wines with increased amounts of EA. The impact of EA on the aging process of premium wines is under research in our lab. 


\section{Acknowledgments}

This work was supported by Fondo Pérez Guerrero para la Cooperación Sur-Sur, Programa de las Naciones Unidas para el Desarrollo (PNUD), Consejo Nacional de Investigaciones Científicas y Técnicas (CONICET) and Facultad de Ciencias Agrarias, Universidad Nacional de Cuyo (Mendoza, Argentina). The authors are grateful for the contribution of wine samples to Eng. Enzo Mugnani Aubone, Msc. Martin Kaiser (Bodega Doña Paula) and Msc. Roció Martin Bravo (Bodega Alpamanta).

\section{References}

[1] Plaza, M., Cifuentes, A., Ibáñez, E., Trends Food Sci.Technol. 2008, 19, 31-39.

[2] Alissa, E. M., Ferns, G. A., Crit. Rev. Food Sci. Nutr. 2017, 57, 1950-1962.

[3] Key, T. J., Br. J. Cancer 2011, 104, 6-11.

[4] Marmot, M., Atinmo, T., Byers, T., Food, nutrition, physical activity, and the prevention of cancer: a global perspective, 2007.

[5] Gul, K., Singh, A. K., Jabeen, R., Crit. Rev. Food Sci. Nutr. 2016, 56, 2617-2627.

[6] Bagchi, D., Nair, S., Developing New Functional Food and Nutraceutical Products, 2016.

[7] Bagchi, D., Preuss, H. G., Swaroop, A., Nutraceuticals and functional foods in human health and disease prevention, CRC Press 2015.

[8] Cook, M. T., Tzortzis, G., Charalampopoulos, D., Khutoryanskiy, V. V., J. Controlled Release 2012, $162,56-67$.

[9] Vaquero, M. J. R., Alberto, M. R., de Nadra, M. C. M., Food Control 2007, 18, 93-101.

[10] Pezzuto, J. M., J. Agric. Food Chem. 2008, 56, 6777-6784.

[11] Xia, E., He, X., Li, H., Wu, S., Li, S., Deng, G., Polyphenols in Human Health and Disease 2013, pp. 47-58.

[12] Yokozawa, T., Kim, Y. A., Kim, H. Y., Lee, Y. A., Nonaka, G. i., Food Chem. Toxicol. 2007, 45, 19791987. 
[13] Meyer, A. S., Yi, O. S., Pearson, D. A., Waterhouse, A. L., Frankel, E. N., J. Agric. Food Chem. $1997,45,1638-1643$.

[14] Vauzour, D., Rodriguez-Mateos, A., Corona, G., Oruna-Concha, M. J., Spencer, J. P. E., Nutrients 2010, 2, 1106-1131.

[15] Sanadgol, N., Golab, F., Tashakkor, Z., Taki, N., Moradi Kouchi, S., Mostafaie, A., Mehdizadeh, M., Abdollahi, M., Taghizadeh, G., Sharifzadeh, M., Pharm. Biol. 2017, 55, 1679-1687.

[16] Pisano, P. L., Silva, M. F., Olivieri, A. C., Food Chem. 2015, 175, 174-180.

[17] Anesi, A., Stocchero, M., Dal Santo, S., Commisso, M., Zenoni, S., Ceoldo, S., Tornielli, G. B., Siebert, T. E., Herderich, M., Pezzotti, M., Guzzo, F., BMC Plant Biology 2015, 15, 191.

[18] Prakash, D., Suri, S., Upadhyay, G., Singh, B. N., Int. J. Food Sci. Nutr. 2007, 58, 18-28.

[19] Papoutsi, Z., Kassi, E., Tsiapara, A., Fokialakis, N., Chrousos, G. P., Moutsatsou, P., J. Agric. Food Chem. 2005, 53, 7715-7720.

[20] Masamune, A., Satoh, M., Kikuta, K., Suzuki, N., Satoh, K., Shimosegawa, T., Biochem. Pharmacol. 2005, 70, 869-878.

[21] Umesalma, S., Sudhandiran, G., Basic Clin. Pharmacol. Toxicol. 2010, 107, 650-655.

[22] Heber, D., Cancer Lett. 2008, 269, 262-268.

[23] Seeram, N. P., J. Agric. Food Chem. 2008, 56, 630-635.

[24] Shin, M. S., Kang, E. H., Lee, Y. I., Antiviral Res. 2005, 67, 163-168.

[25] Goodwin, E. C., Atwood, W. J., DiMaio, D., J. Virol. 2009, 83, 5630-5639.

[26] Nohynek, L. J., Alakomi, H. L., Kähkönen, M. P., Heinonen, M., Helander, I. M., OksmanCaldentey, K. M., Puupponen-Pimiä, R. H., Nutr. Cancer 2006, 54, 18-32.

[27] Talcott, S. T., Lee, J. H., J. Agric. Food Chem. 2002, 50, 3186-3192.

[28] Jordão, A. M., Ricardo-Da-Silva, J. M., Laureano, O., Mullen, W., Crozier, A., Aust. J. Grape Wine Res. 2008, 14, 260-270.

[29] Masson, G., Moutounet, M., Puech, J. L., Am. J. Enol. Vitic. 1995, 46, 262-268.

[30] Prida, A., Puech, J. L., J. Agric. Food Chem. 2006, 54, 8115-8126.

[31] Arráez-Román, D., Fu, S., Sawalha, S. M. S., Segura-Carretero, A., Fernández-Gutiérrez, A., Electrophoresis 2010, 31, 2289-2296.

[32] Giusti, F., Caprioli, G., Ricciutelli, M., Vittori, S., Sagratini, G., Food Chem. 2017, 221, 689-697.

[33] Martí, R., Valcárcel, M., Herrero-Martínez, J. M., Cebolla-Cornejo, J., Roselló, S., Food Chem. 2017, 221, 439-446.

[34] Matei, A. O., Gatea, F., Teodor, E. D., Radu, G. L., Rev. Chimie 2016, 67, 1051-1055.

[35] Gomez, F. J. V., Hernández, I. G., Cerutti, S., Silva, M. F., Microchemical Journal 2015, 123, 22-27.

[36] Costa, E. V., Lima, D. L. D., Evtyugin, D. V., Esteves, V. I., Wood Sci. Technol. 2014, 48, 99-108. 
[37] Springer, V. H., Lista, A. G., Electrophoresis 2012, 33, 2049-2055.

[38] Dopico-García, M. S., Fique, A., Guerra, L., Afonso, J. M., Pereira, O., Valentão, P., Andrade, P. B., Seabra, R. M., Talanta 2008, 75, 1190-1202.

[39] See, H. H., Marsin Sanagi, M., Ibrahim, W. A. W., Naim, A. A., J. Chromatogr. A 2010, 1217, 17671772.

[40] Muñoz-Muñoz, J. L., Garcia-Molina, F., Garcia-Molina, M., Tudela, J., García-Cánovas, F., Rodriguez-Lopez, J. N., IUBMB Life 2009, 61, 171-177.

[41] Fernández, M. D. L. Á., Espino, M., Gomez, F. J. V., Silva, M. F., Food Chem. 2018, 239, 671-678.

[42] Gomez, F. J. V., Hernández, I. G., Martinez, L. D., Silva, M. F., Cerutti, S., Electrophoresis 2013, $34,1749-1756$. 
Figure 1: (A) Electropherogram. (B) Chromatogram of polyphenol standards. (C) Electropherogram of a wine sample Malbec. Conditions CE: BGE: Boric Acid $30 \mathrm{mmol} \mathrm{L}^{-1} 10 \% \mathrm{MeOH}\left(v v^{-1}\right) p H=9.10$, capillary: $57 \mathrm{~cm}$ full length, $50 \mathrm{~cm}$ effective length, $75 \mu \mathrm{m} I D$ and $375 \mu \mathrm{m}$ OD; hydrodynamic injection 10 mbar, $3 \mathrm{~s} ; 20 \mathrm{kV}$ constant voltage; $T: 20{ }^{\circ} \mathrm{C}, \lambda=254 \mathrm{~nm}$. Conditions HPLC: mobile phase: $A$ Water $0.1 \%$ Formic acid, B ACN; Elution mode in gradient; flow $1 \mathrm{~mL} \mathrm{~min}{ }^{-1}$; Column Zorbax SB-Aq column (4.6 mm x $150 \mathrm{~mm}, 5 \mu \mathrm{m})$, column T: $20^{\circ} \mathrm{C}$; Injection: $5 \mu \mathrm{L} ; \lambda=254 \mathrm{~nm}$. Gal: Galic Acid; Van: Vanilic Acid; Syr: Syringic Acid; EA: Ellagic Acid; Sin: Sinapinic acid; Cin: Cinnamic acid; Q: Quercetin.
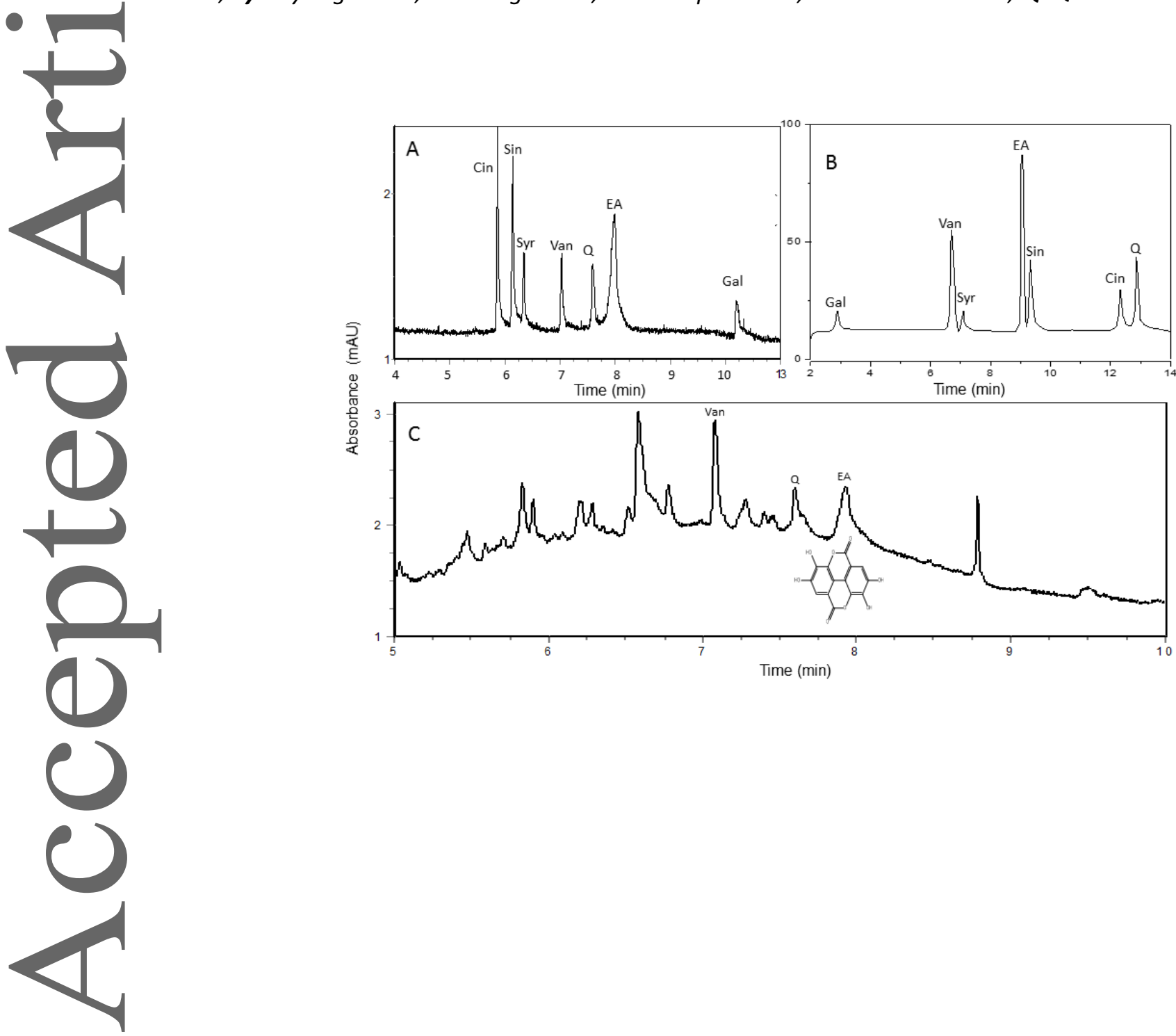

This article is protected by copyright. All rights reserved. 
Figure 2: Mean concentration for EA in all Malbec samples under study for the different aging conditions.

Values with different letters present significant differences $P \leq 0.05$.

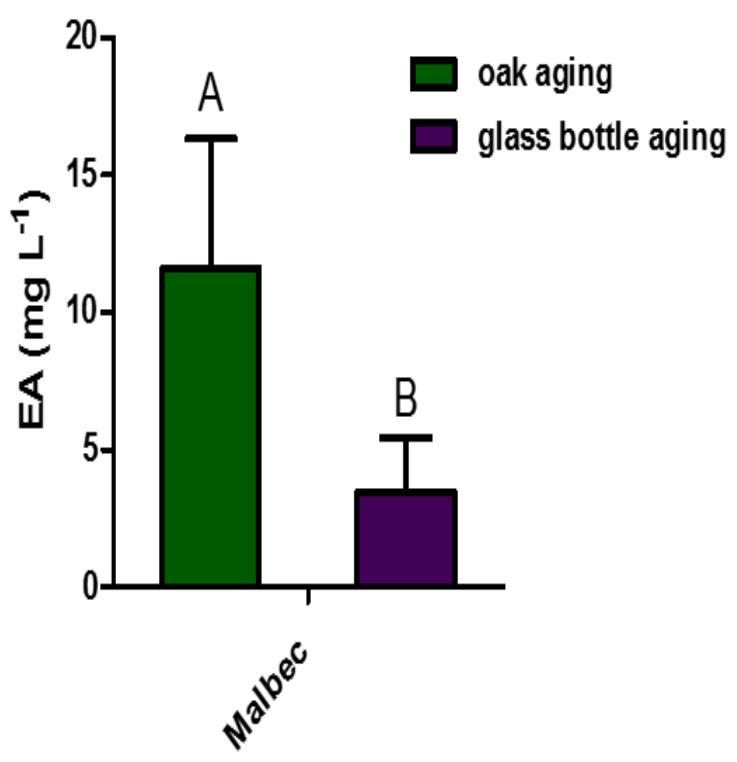


Table 2 Concentration of EA detected in wine samples.

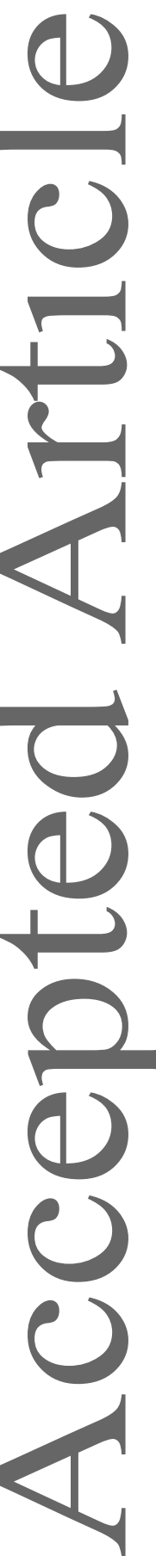

\begin{tabular}{|c|c|c|c|c|c|}
\hline $\begin{array}{l}\text { Sample } \\
\text { wine }\end{array}$ & Varietal & Vintage & $\begin{array}{l}\text { Aging in oak } \\
\text { (months) }\end{array}$ & $\begin{array}{c}C E \\
E A\left(\mathrm{mg} \mathrm{L}^{-1}\right)\end{array}$ & $\begin{array}{c}\text { HPLC } \\
\text { EA }\left(\mathrm{mg} \mathrm{L}^{-1}\right)\end{array}$ \\
\hline 1 & Malbec & 2015 & No & $3.65 \pm 0.87$ & $4.05 \pm 0.82$ \\
\hline 2 & Malbec & 2010 & No & $4.17 \pm 0.49$ & $3.96 \pm 0.42$ \\
\hline 3 & Malbec & 2014 & No & $4.19 \pm 0.34$ & $4.10 \pm 0.31$ \\
\hline 4 & Malbec & 2016 & 3 & $4.26 \pm 1.96$ & $4.89 \pm 1.82$ \\
\hline 5 & Malbec & 2016 & 3 & $4.78 \pm 1.03$ & $5.45 \pm 1.12$ \\
\hline 6 & Malbec & 2015 & 6 & $\mathrm{~N} / \mathrm{D}$ & $\mathrm{N} / \mathrm{D}$ \\
\hline 7 & Malbec & 2015 & 10 & $5.29 \pm 0.31$ & $5.50 \pm 0.47$ \\
\hline 8 & Malbec & 2012 & 10 & $10.60 \pm 0.68$ & $10.92 \pm 0.72$ \\
\hline 9 & Malbec & 2010 & 10 & $10.93 \pm 0.71$ & $11.52 \pm 0.69$ \\
\hline 10 & Malbec & 2015 & 10 & $15.86 \pm 0.53$ & $15.54 \pm 0.52$ \\
\hline 11 & Malbec & 2015 & 10 & $17.65 \pm 3.21$ & $16.38 \pm 3.10$ \\
\hline 12 & Cabernet Suavignon & 2012 & No & $3.56 \pm 0.27$ & $3.74 \pm 0.25$ \\
\hline 13 & Cabernet Sauvignon & 2014 & 10 & $6.50 \pm 2.27$ & $5.22 \pm 1.75$ \\
\hline 14 & Cabernet Suavignon & 2015 & 10 & $7.95 \pm 2.05$ & $8.50 \pm 1.98$ \\
\hline 15 & Cabernet Franc & 2013 & 10 & $2.71 \pm 0.44$ & $2.54 \pm 0.41$ \\
\hline 16 & Cabernet Franc & 2015 & 10 & $3.81 \pm 0.52$ & $3.88 \pm 0.51$ \\
\hline 17 & Cabernet Franc & 2015 & 10 & $5.17 \pm 0.68$ & $5.28 \pm 0.56$ \\
\hline 18 & Merlot & 2012 & No & $\mathrm{N} / \mathrm{D}$ & $0.07 \pm 0.04$ \\
\hline 19 & Merlot & 2015 & 10 & $8.24 \pm 0.72$ & $7.91 \pm 0.74$ \\
\hline 20 & Merlot & 2015 & 10 & $9.66 \pm 2.89$ & $8.51 \pm 2.73$ \\
\hline 21 & Pinot Noir & 2015 & 10 & $10.21 \pm 1.90$ & $11.13 \pm 1.85$ \\
\hline 22 & Chardonay & 2015 & 10 & $\mathrm{~N} / \mathrm{D}$ & $\mathrm{N} / \mathrm{D}$ \\
\hline
\end{tabular}

This article is protected by copyright. All rights reserved. 


\begin{tabular}{|c|c|c|c|c|c|}
\hline 23 & Chardonay & 2015 & 3 & N/D & N/D \\
\hline 24 & Torrontes & 2013 & No & $\mathrm{N} / \mathrm{D}$ & $\mathrm{N} / \mathrm{D}$ \\
\hline 25 & Torrontes & 2015 & No & $\mathrm{N} / \mathrm{D}$ & $\mathrm{N} / \mathrm{D}$ \\
\hline 26 & Suavignon Blanc & 2012 & No & $\mathrm{N} / \mathrm{D}$ & $\mathrm{N} / \mathrm{D}$ \\
\hline 27 & Suavignon Blanc & 2015 & No & $\mathrm{N} / \mathrm{D}$ & $\mathrm{N} / \mathrm{D}$ \\
\hline 28 & Syrah & 2010 & No & $\mathrm{N} / \mathrm{D}$ & $\mathrm{N} / \mathrm{D}$ \\
\hline 29 & Syrah & 2014 & 10 & $\mathrm{~N} / \mathrm{D}$ & $\mathrm{N} / \mathrm{D}$ \\
\hline 30 & Pedro Gimenez & 2015 & No & $\mathrm{N} / \mathrm{D}$ & $\mathrm{N} / \mathrm{D}$ \\
\hline
\end{tabular}

